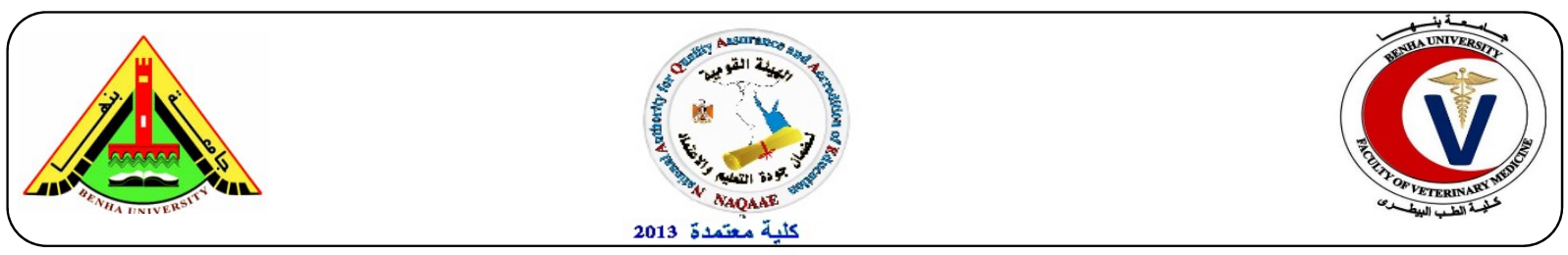

\title{
Determination of the optimal protective dose of inactivated Salmonella Typhimurium vaccine in pigeon
}

\author{
Afaf, A. Khedr, Anhar, A. Abdel latef, Sayed, M.L. and Salama, S.S. \\ Central Laboratory for Evaluation of Veterinary Biologics, Abbasia, Cairo Egypt
}

\begin{abstract}
A B S T R A C T
Salmonellosis is one of the major health problem affect pigeons and protection of pigeons against this disease is very important, for this purpose the present work was planned to prepare an inactivated Montanide ISA- 206 oil adjuvant vaccine from a locally pigeon isolate of Salmonella Typhimurium (S. Typhimurium) and determined of the optimal dose, which protect pigeon against salmonellosis. Evaluation of such preparation following the quality control tests revealed that it was free from any foreign contaminants, safe and immunogenic. Pigeons were divided into six groups, three of them vaccinated subcutaneously with single dose $(0.5 \mathrm{ml})$ of different bacteria concentrations $\left(10^{8}, 10^{9}\right.$ and $10^{10} \mathrm{CFU} /$ dose) and the others three received 2 doses with 3 weeks intervals with same route and concentrations. The vaccination/challenge assay with a virulent $S$. typhimurium organism using $5 \times 10^{7} \mathrm{CFU} /$ dose revealed that protection rates of vaccinated birds were $70 \%, 75 \%$ and $75 \%$ for the first three groups (Ia, IIa, IIIa) respectively, while the other three groups gave $80 \%, 85 \%$ and $85 \%$ protection( $\mathrm{Ib}$, IIb, IIIb) respectively.Control groups could not withstand the challenge and protection rate were $15 \%$ and $20 \%$ respectively. The seroevaluation showed that the humoral immune response developed against $S$. typhimurium in vaccinated pigeons was high. On conclusion the optimal dose of the prepared vaccine should be $10^{9} \mathrm{CFU} /$ dose applied twice with three weeks interval, which can cover the needed requirements and protect pigeon against salmonellosis.
\end{abstract}

Keywords: S. Typhimurium, pigeon, vaccine, humoral immune response

(http://www.bvmj.bu.edu.eg)

(BVMJ-31(1): 73-77, 2016)

\section{INTRODUCTION}

Salmonella are host-adapted, zoonotic human and animal pathogens (Libby et al. 2004). The disease caused by this organeasm in pigeons is a major bacterial disease, resulting in mortality in squabs and occasional deaths in adult in infected pigeon lofts. More or less severe clinical signs, including weight loss, diarrhoea, polyuria, lameness and inability to fly are more common. Treatment of infected flocks is difficult since even long-term antibiotic therapy may leave subclinical carriers that keep the Salmonella infection in the loft going (Monita Vereecken et al., 2000). Bacterin vaccines proved unable to prevent initiation of Salmonella infections in pigeons (Uyttebroek et al., 1991) and vaccinated birds developed clinical signs and lesions during infection. For this reason, effective prevention of salmonellosis in pigeons through vaccination is not yet available. Recently, a newly developed Salmonella bacterin vaccine has been marketed. Duchatel et al. 1998 demonstrated a significant decrease of mortality in pigeons vaccinated with this vaccine following intramuscular challenge with Salmonella typhimurium var. Copenhagen. The objectives of the present study were to prepare an inactivated oil-emulsion bacterin from a local pigeon isolate of Salmonella typhmirium and evaluation of this vaccine through determination of the optimal dose, evaluate its efficacy for protecting pigeon against salmonellosis under experimental conditions and monitoring the humoral immune response in vaccinated and unvaccinated birds..

\section{MATERIALS AND METHODS}

\subsection{Pigeons:}

A total of two hundred and seventy 4 weeks age Pigeons obtained from a commercial pigeonbreeding centre, Kept under strict hygienic measure of rearing and feeding. Cloacal swabs and blood samples were collected from pigeon to confirm that they were free from Salmonella typhimurium bacteria or antibodies.

\subsection{Vaccine preparation}


Alocal pigeon isolate of Salmonella typhimurium, was kindly obtained from Centeral laboratory for evaluation of veterinary biologces (CLEVB). This strain was identified morphologically, culturally, biochemically and serologically following the method adapted by (Nagraja et al. 1991).The strain was grown on tryptic soya agar (Difco) for $48 \mathrm{hr}$ at $37^{\circ} \mathrm{C}$. Bacteria was harvested in normal saline, and the concentration of bacterial suspension was adjusted to contain $10^{8}, 10^{9}$ and $10^{10} \mathrm{CFU} /$ dose. The purity of culture was examined by inoculation on to brilliant green agar plat (Difco). The bacterial culture was inactivated by adding $0.3 \%$ formalin with agitation then the inactivation was ensured by plating onto nutrient agar and incubation at $37 \mathrm{c}^{\circ}$ for $24 \mathrm{hrs}$. Montanide ISA- 206 was added to the diffearent concentration culturs in equale volume $(\mathrm{v} / \mathrm{v})$ and mixed thoroughly according to (Steward,1983).

\subsection{Experimental Design:}

Two hundred and seventy pigeons were used in this expermintet. 30 pigeons were used for the safety testing while the rest (240 pigeons) were divided into different groups as following table.

Table (1): Experimental Design:

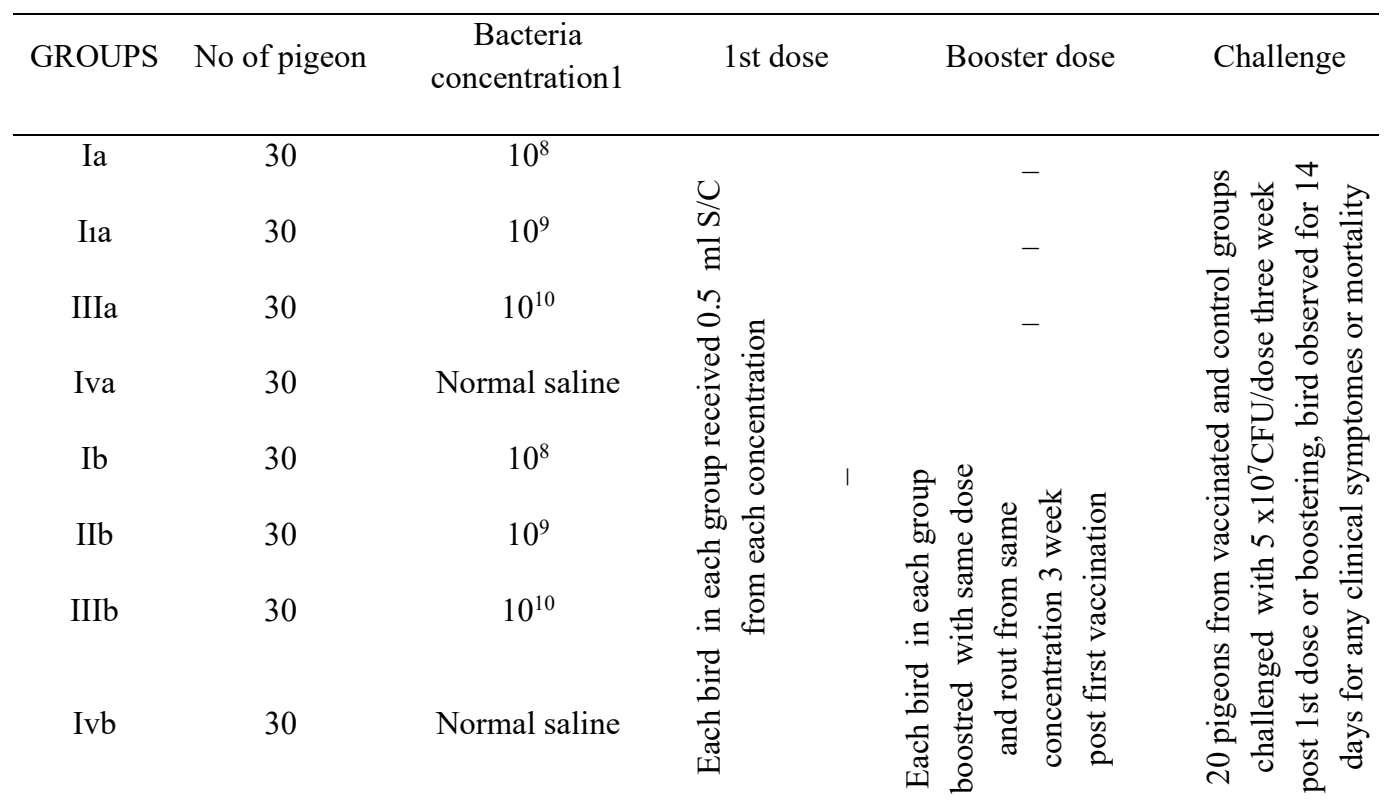

N.B: Ten pigeon from each concentration in each group were left without challenge for seroevaluation (goup Ic,IIC and IIIc) for 3 weeks in group vaccinated with single dose and for 7 weeks in groups vaccinated with booster dose.

\subsection{Evaluation of locally prepared inactivated Salmonella typhmiurium vaccines}

a. Sterility tests:

The prepared vaccines were tested for freedom from any bacteria, fungi and mycoplasma contaminant, according to (OIE, 2012).

\section{b. Safety test:}

Ten birds were inoculated with the double feild dose $\mathrm{s} / \mathrm{c}$ of each concentration $\left(10^{8}, 10^{9}\right.$ and $10^{10}$ $\mathrm{CFU} /$ dose) and kept under daily observation for 14 days. according to (OIE, 2012)

\section{c. Potency tests:}

Protection rates of the prepared Montanide ISA 206 vaccine of Salmonella typhmirium vaccine containing $10^{8}, 10^{9}$ and $10^{10} \mathrm{CFU} /$ dose were carried out primarily by using the vaccination/challenge test.

\section{Serological evaluation:}

Seroevaluation of immune response was adopted for all groups where serum samples were collected from vaccinated as well as control group and humoral immune response developed against $\mathrm{S}$. Typhimurium tested by microagglutination test .according to (Brown et al. 1981).

\section{Challenge test:}


Twenty pigeons from vaccinated and control groups were evaluated through vaccination/challenge test by inoculation $0.1 \mathrm{ml}$ intramuscularly of virulent strain of Salmonella typhmirium serovar typhi in a concentration of 5 $\mathrm{x} 10^{7} \mathrm{CFU} /$ dose three weeks post first dose or booster dose of the prepeard vaccine as in table(3). The virulent strain was obtained from CLEVB, Abassia. Cairo, Egypt . Birds were kept under observation three weeks post challenge exposing mortality and disease symptoms OIE Manual (2012).

\subsection{Reisolation of challenge strain from challenged birds:}

Samples were taken from internal organs (liver, heart and spleen) of mortality cases and birds showed symptoms of salmonellosis postchallenge. These samples were preenriched then streaked onto MaConkey and Salmonella shigella agar media.

\section{RESULT}

Regarding the humoral antibody responses, it was checked using micro-agglutination test and the antibody titers were calculated as shown in Table (2). The level of antibody in sera of pigeons vaccinated with local inactivated vaccines of Salmonella typhimurium increased in group I, II and III, 3 weeks post the 1st dose of vaccination and reach to maximum at the $5^{\text {th }}$ week post boostering in the same groups. The protection efficacy of the local prepared Salmonella typhimurium vaccines in pigeons are shown in table (3).

Table (2): Mean antibody titer of microagglutination test in the pigeons vaccinated with locally prepared inactivated montanied ISA 206 Salmonella typhimurium vaccines.

\begin{tabular}{|c|c|c|c|c|c|c|c|c|c|c|c|}
\hline \multirow{2}{*}{ 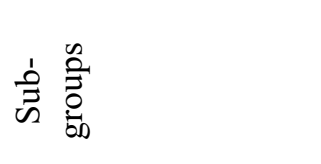 } & \multirow{2}{*}{ 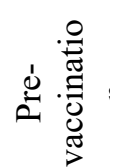 } & \multicolumn{3}{|c|}{ Weeks post 1 st dose } & \multicolumn{7}{|c|}{ Weeks post boostering } \\
\hline & & 1 & 2 & 3 & 1 & 2 & 3 & 4 & 5 & 6 & 7 \\
\hline (Ic) & 0 & 4 & 8 & 32 & 32 & 64 & 128 & 128 & 128 & 128 & 64 \\
\hline (IIc) & 0 & 8 & 32 & 64 & 64 & 128 & 128 & 128 & 256 & 128 & 128 \\
\hline (IIIc) & 0 & 16 & 32 & 64 & 64 & 128 & 128 & 256 & 256 & 128 & 128 \\
\hline Control unvaccinated & 0 & 0 & 0 & 0 & 0 & 0 & 0 & 0 & 0 & 0 & 0 \\
\hline
\end{tabular}

Table (3): Protective percentage of local mantonide ISA 206 Salmonella typhimurium vaccines in pigeon challenged with virulent $S$. typhimurium strain.

\begin{tabular}{|c|c|c|c|c|c|c|c|c|c|}
\hline \multirow{4}{*}{ Groups } & \multicolumn{9}{|c|}{ Protection Percent post challenge } \\
\hline & \multirow{2}{*}{\multicolumn{4}{|c|}{$\begin{array}{l}\text { 1st dose } \\
\text { Survival }\end{array}$}} & \multirow[b]{3}{*}{$\begin{array}{l}\text { Sub- } \\
\text { groups }\end{array}$} & \multirow{2}{*}{\multicolumn{4}{|c|}{$\begin{array}{c}\text { Boostering } \\
\text { Survival }\end{array}$}} \\
\hline & & & & & & & & & \\
\hline & Mortality & $\begin{array}{l}\text { With } \\
\text { lesions }\end{array}$ & $\begin{array}{l}\text { With } \\
\text { out } \\
\text { lesions }\end{array}$ & $\begin{array}{c}\text { Protection } \\
\%\end{array}$ & & Mortaltiy & $\begin{array}{l}\text { With } \\
\text { lesions }\end{array}$ & $\begin{array}{l}\text { Without } \\
\text { lesions }\end{array}$ & $\begin{array}{c}\text { Protection } \\
\%\end{array}$ \\
\hline $\begin{array}{l}\text { (Ia) } \\
\left(10^{8} / \text { dose }\right)\end{array}$ & $3 / 20$ & $3 / 20$ & $14 / 20$ & $70 \%$ & $\begin{array}{c}(\mathrm{Ib}) \\
10^{8} / \text { dose }\end{array}$ & $2 / 20$ & $2 / 20$ & $16 / 20$ & $80 \%$ \\
\hline $\begin{array}{l}\text { (IIa) } \\
\left(10^{9} / \text { dose }\right)\end{array}$ & $3 / 20$ & $2 / 20$ & $15 / 20$ & $75 \%$ & $\begin{array}{c}(\mathrm{IIb}) \\
10^{9} / \text { dose }\end{array}$ & $0 / 20$ & $3 / 20$ & $17 / 20$ & $85 \%$ \\
\hline $\begin{array}{l}\text { (IIIa) } \\
\left(10^{10} / \text { dose }\right)\end{array}$ & $4 / 20$ & $1 / 20$ & $15 / 20$ & $75 \%$ & $\begin{array}{c}\text { (IIIb) } \\
10^{10} / \text { dose }\end{array}$ & $1 / 20$ & $2 / 20$ & $17 / 20$ & $85 \%$ \\
\hline $\begin{array}{l}\text { Control } \\
\text { unvaccinated }\end{array}$ & $7 / 20$ & $10 / 20$ & $3 / 20$ & $15 \%$ & control & $6 / 20$ & $10 / 20$ & $4 / 20$ & $20 \%$ \\
\hline
\end{tabular}




\section{DISCUSSION}

It is widely known that the number of cases of Salmonella related food poisoning have increased year after year over the past decade. Salmonellae are responsible for considerable losses in the poultry industry through the death of birds and loss in production and it is estimated to cost poultry farmers in some countries (Hassan et al., 2013). Vaccination is one of the most important methods for prevention of Salmonellosis. There has been an increasing interest in using Salmonella vaccination in poultry especially against the serovars of major public health relevance; S. Enteritidis and S. Typhimurium.. Inactivated and/or live Salmonella vaccines are in use for poultry in a number of countries (Vielitz et al., 1992). Many racing pigeons carry Salmonella asymptomatically in their bowels. The stressors associated with racing can act as trigger factors enabling the bacteria to penetrate the bowel wall and spread throughout the body causing a range of symptoms that compromise race performance For control of Salmonella infected pigeon flocks, not only is the clinical disease to be avoided, but it is also necessary to inhibit excretion of the organism since this could maintain the infection (Monita et al., 2000). The locally prepared S. Typhimurium vaccine in this study was free from bacterial, fungal and mycoplasma contaminant and it was safe when injected in a doubled dose in pigeons for all concentration used .

Regarding the humoral antibody responses, it was checked using micro-agglutination test and the antibody titers were calculated.

The level of antibody in sera of pigeons vaccinated with local inactivated vaccines of Salmonella typhimurium increased from 0 titer prevaccination to be 32, 64, and 64 against Salmonella typhimurium in the group Ic, IIc and IIIc respectively 3 weeks post the 1 st dose of vaccination and reach to maximum at the $5^{\text {th }}$ week post boostering in the same groups $(128,256$ and 256) respectively. These results coincide with that proved by Nagraja et al. (1991).

Challenge test is considered the master test for determination of the protective value of a vaccine (Timms et al., 1990). Concerning the protection efficacy of the local prepared Salmonella typhimurium vaccines in pigeons, the data showed that protection rates for pigeons received single dose were $70 \% 75 \%$ and $75 \%$ in the group Ia, IIa and IIIa respectively. While the protection rate was $80 \% 85 \%$ and $85 \%$ in the group Ib, IIb and IIIb respectively for pigeons received doubled dose.
While control group IV gave only $15 \%$ and $20 \%$ protection under the same conditions.

The achieved protection values by the prepared vaccines are accepted to pass the vaccine for use according to Egyptian Veterinary Codex- CLEVB (2009).

The challenge strain was re-isolated from internal organs of all mortality cases and pigeons showed symptoms of salmonellosis post-challenge.

The prepared inactivated formalized $\mathrm{S}$. typhimurium vaccine was safe and effective and that agree with (Barrow 1991) who stated that inactivated vaccine of avian salmonellosis is protective against Salmonella infection. Also these results came confirming by those of Timms et al. (1990) and Uyttebroek et al. (1991) who found that formalized $\mathrm{S}$. typhimurium vaccine protected pigeons against experimental challenge. From above obtained data in this study it could be concluded that the optimal dose of the prepared vaccine should be $10^{9} \mathrm{CFU} /$ dose applied twice with three weeks interval, which can cover the needed requirements and protect pigeon against salmonellosis.

\section{REFERENCES}

Barrow, P.A. 1991. Experimental infection of chickens with Salmonella Enteritidis. Avian Pathol. Mar; 20 (1), 145-53.

Brown, S.L., F.T. Klin and W.L. Jones 1981. Safranin "O" stained antigen microagglutination test for detection of Brucella antibodies. J. Clin. Microbiol., 13, 398-400.

Duchatel, J.P., De Ree, J.M. and Vindevogel, H. 1998. Evaluation of the optimal vaccine dose for vaccination trials of pigeons against paratyphosis by subcutaneous injection of different inactivated aqueous adjuvanted vaccines. Annales de médecine vétérinaire. 142(1), 35-38.

Duchatel, J.P., De Ree, J.M. and Vindevogel, H. 1998. Essais de vaccination de pigeons contre la paratyphose au moyen de vaccines inactivés en suspension aqueuse: détermination de la dose vaccinale. Annales de Médecine Vétérinaire, 142, 35-38.

Egyptian Veterinary Codex CLEVB 2009. Testing for Extraneous Agents, pp. 1-11.

Hassan, W.H., Shafey S.M. and Marwa M.S. Khedr 2013. Immunological studies on local and imported mineral o1l vaccines against paratyphoid in broiler chickens. International Journal of Microbiological Research 4(1), 69-76. 
Libby, S. J., Halsey, T. A, Potter, J. and C. L. Gyles. 2004. Pathogenesis of bacterial infections in animals. $3^{\text {rd }}$ Edition Chapter 14, 143-167.

Monita Vereecken, Peter De Herdt Ugent, Richard Ducatelle Ugent and Freddy Haesebrouck Ugent 2000, The effect of vaccination on the course of an experimental Salmonella typhimurium infection in racing pigeons. Avian Pathology, 29(5), 465-471.

Nagraja, K.V., Kumer, M.C. and Pomeroy, B.S. 1991. Is vaccination a feasible approach for control of Salmonella. Proceeding Conference "Colonization Control of Human Bacterial Enteropathogenesis in Poultry", pp. 243-256.

OIE manual 2012. Manual of standards of diagnostic test and vaccines for terrestrial animals safety test.
Steward Tull 1983. DES in Biology of Microbacteria, Vol. 2, Academic press, London.

Timms, L.M., Marshall, R.N., Breslin, M.F. 1990. Laboratory assessment of protection given by an experimental Salmonella enteritidis PT4 inactivated, adjuvant vaccine. Vet. Rec. 127, 611-614.

Uyttebroek, E., Devriese, L.A., Gevaert, D., Ducatelle, R., Nelis, J. and Haesebrouck, F. 1991. Protective effects of vaccines against experimental salmonellosis in racing pigeons. The Veterinary Record, 128, 152153.

Vielitz, E., Conrad, C., Voss, M., Löhren, U., Bachmeier, J. and Hahn, I. 1992. Immunization against Salmonella infections using live and inactivated vaccine preparations. Dtsch. Tierärztl. Wschr., 99, 483-485. 